Geopolítica(s) Revista de estudios sobre espacio y poder ISSN: 2172-3958

https://dx.doi.org/10.5209/geop.70011

\title{
Campos, redes y fronteras del poder
}

Marcela Friedberg, Mario Nave y Rosa Ramírez (Eds.) (2018) Claude Raffestin: territorio, frontera, poder. Barcelona: Icaria, 304 pp. ISBN: 978-84-9888-8416.

Este libro dedicado a Claude Raffestin fue publicado en octubre de 2018 por Icaria Editorial como parte de la colección multidisciplinaria "Espacios Críticos", dirigida a autores que examinan críticamente la realidad desde una perspectiva espacial. Al recorrer el itinerario elegido por los organizadores de la recopilación, que consta de cinco capítulos, expongo algunos de los aspectos que destacaron en el trabajo del geógrafo suizo. Un autor, como afirman, cuya recepción en España es "escasa e irregular, y su trabajo aún es poco conocido" (p.8). Este es uno de los aspectos importantes del libro publicado en castellano, que cuenta con una investigadora catalana entre sus editoras.

Como revelan los organizadores en la introducción del libro, la tarea de preparar la recopilación distaba mucho de ser fácil, tanto por la "estructura laberíntica" del trabajo de Raffestin (p.5) como por la imposibilidad de "separar su pensamiento o figura pública de su profunda honestidad intelectual y humanidad" (p.8). Quizás, por esta razón, los organizadores no han evitado usar recuerdos personales de sus reuniones con el autor homenajeado para seleccionar los textos y, en cada una de sus partes, enfatizar sus contribuciones al pensamiento geográfico. Es un libro que efectivamente acerca a los lectores de la lengua castellana a un autor de "escritura densa y fascinante" (p.6), "difícil, pero agudo y estimulante" (p.9).

Aunque recientemente descubierto por la geografía anglosajona, Raffestin es considerado un geógrafo europeo, ya sea por los lugares donde vivió y trabajó a lo largo de su carrera (Francia, Suiza, Italia) o por su influencia en la formación de generaciones de geógrafos franceses, suizos, italianos, hispanoamericanos y brasileños. Su trabajo hizo posible, entre otras contribuciones, tender un puente entre la tradición crítica y teórica francesa y la de los geógrafos urbanos italianos de izquierda (p.6). Su contribución original al pensamiento geográfico mundial pasa por el enfoque del concepto de paisaje, el modelo TDR (territorialización - desterritorialización - reterritorialización) y la reelaboración de la noción de ecología humana (p.6).

Los tránsitos por Europa y otros lugares del mundo, su biografía y trayectoria académica son el objeto de la primera parte del libro, cuidadosamente escrita por Marcella Friedberg: "Trayectoria intelectual: una búsqueda del sentido de la geografía". Subdividido en cinco temas (exilio, lógica del poder, geografía del poder, 
paisaje y sistema), el capítulo recorre cronológicamente la vida del autor desde la experiencia del exilio - que incluso marcó su desarrollo intelectual- hasta los exponentes de su producción teórica, cuyo momento cumbre es la publicación, en 1980, del famoso libro Pour une géographie du pouvoir.

Claude Raffestin nació en París (1936), pero en 1958 adoptó la ciudadanía suiza. "Hijo de la guerra", a los 14 años se mudó a Ginebra con su madre y su padrastro. La experiencia del exilio es un tema recurrente en su trayectoria, como explica Friedberg. Para enseñar en Suiza y por oponerse a la guerra de Argelia, renunció a la ciudadanía francesa. Exiliado de su tierra natal, también es considerado en la comunidad científica: "un geógrafo a contracorriente" (p.14). Vivió en París, Ginebra y Turín. Ciudadano del mundo, capaz de adaptarse y vivir en diferentes ciudades y lugares, eligió Bodrum (Halicarnaso, Asia) como uno de los lugares más importantes de su experiencia (p.14). Allí, como afirmó el autor, se le reveló uno de los conceptos clave de su trabajo, el paisaje: "Mi di cuenta de que el paisaje que estaba recorriendo construía una continuidad histórico-geográfica que me removía como el mar en medio de una tormenta" (p.15). En Ginebra se licenció en Geografía (1959) y defendió su doctorado (1968) con la tesis Ginebra, ensayo de geografía industrial. La tesis fue premiada y le valió un puesto como investigador, profesor extraordinario y catedrático. Sin embargo, no estaba satisfecho porque hasta ese momento había prestado poca atención a la lógica del poder: "el lenguaje morfofuncional utilizado fue incapaz de comprender el poder y descifrarlo" (p.17). Regresó a este tema en otros períodos de su carrera, consolidando una parte sustancial de su pensamiento al respecto con la publicación de Pour une géographie du pouvoir.

De manera minuciosa y detallada, la primera parte del libro aborda con éxito la totalidad del trabajo de Raffestin, recomponiéndolo como un mosaico y ofreciendo importantes contribuciones para la contextualización de cada una de sus publicaciones más importantes. En las páginas 20-21, por ejemplo, el autor ofrece a los lectores un cuadro sinóptico en el que destaca la superposición entre eventos históricos, libros clave del período, las experiencias del autor en diferentes partes del mundo (como Quebec y Haití), los campos de estudio al que se dedicó, las influencias teóricas y los trabajos publicados por él. Además de la exposición densa del capítulo, la sinopsis permite una visión amplia y contextualizada del autor, especialmente para aquellos que aún no lo conocen. Paisaje, territorialidad, vida cotidiana, frontera, espacio fronterizo, trabajo y poder son algunos de los variados temas explorados por Raffestin con seriedad metodológica, curiosidad inagotable y pasión por la "geografía como conocimiento científico vivo" (Raffestin apud, p.50).

La segunda parte del libro, "Conversando con Claude Raffestin: «la imagen de su cara»", está dedicada a una entrevista realizada por los organizadores de la recopilación con el autor, en Turín, en enero de 2014. Reaparecen, esta vez en la voz del propio homenajeado, temas como la ciudadanía internacional, la influencia de la literatura - a la que los organizadores del libro recurren a menudo para ilustrar la biografía y el pensamiento de Raffestin-, la lingüística, las múltiples direcciones que tomaron sus investigaciones a lo largo de su trayectoria, la relación con Ginebra y con la geografía anglosajona. 
Una antología de 10 textos ya publicados constituye la tercera parte del libro: "Antología de textos de Claude Raffestin". De manera ejemplar, los organizadores problematizan y articulan la trayectoria del autor, los temas a los que se dedicó y sus publicaciones, un movimiento que impregna cuidadosamente toda la colección y también se manifiesta en la elección de los textos de la antología, previamente presentados y contextualizados en los capítulos anteriores. De este modo, esta antología es otra contribución importante a la difusión de las publicaciones de Raffestin en castellano. La elección de los textos se guió por la intención de ser representativos de la multiplicidad de caminos abiertos por cada una de las nociones exploradas por el autor.

La cuarta parte consiste en un texto inédito: "Elementos sobre los fundamentos de la geografía o ensayo de identificación de la geograficidad", traducida del francés por Rosa Cerarols. En él, Claude Raffestin se dedica a historizar el concepto de geograficidad (p.263). Para hacer esto, recurre a la historia del pensamiento geográfico, a partir de los postulados de la Geografía Física de Kant, para quien el término evocaba "todo lo relacionado con la actividad del geógrafo" (p.265). Sin embargo, Raffestin va más allá en su intención y propone explicar la distinción entre una geografía de la representación y otra geografía de la acción (p.266). En el caso del primero, usa a Dardel y su concepción de que el pensamiento geográfico está orientado hacia la interpretación de la presencia del sujeto en la Tierra. Por lo tanto, la historia, la expresión individual, el conocimiento, el mito y el arte no se disociarían de la geografía como representación, como lo ejemplifica el autor al mencionar a Eratóstenes, Estrabón, Alberto el Grande y Varenio (pp.266-267).

La geografía de la acción se califica a través de los supuestos de Reclus, destacando la forma en que la acción humana "se impone al medio ambiente" (p.267). También es mediante este último autor que Raffestin diferencia la representación y la acción como diferentes estados de la geograficidad: pasivo y activo, respectivamente. El estado activo de la geografía tiene en cuenta, por lo tanto, "lo que los seres humanos a lo largo del tempo hacen de lo que han recibido como algo compartido" (p.268). Sin embargo, no son estados opuestos o separados, sino que forman un continuum, ya que, como argumenta Reclus, es desde el estado pasivo que "los seres humanos desarrollan los elementos terrestres en función de las culturas de que disponen" (p.268). De hecho, argumenta Raffestin, la experiencia de la geografía siempre es parcial, ya que depende del observador o del autor, y se revela gradualmente de acuerdo con la historicidad (p.269). Esto se atribuye a la causa probable de la "multiplicación de geografías". Y, en este punto, es evidente la posición del autor en contra de la multiplicación de nichos o denominaciones basadas en temas. En su opinión, esto habría debilitado, por difusión, los principios explicativos de la geografía. Y es en este argumento que el autor se centra en la última parte del capítulo cuando explica dos principios fundamentales para la geografía: densidad y concentración (p.270).

Es evidente en el texto la preocupación del autor por revisar la historia del pensamiento geográfico con extremo rigor y ambición de proponer "una geografia sin adjetivo" (p.271) comprometida con la elaboración de una "geografía general" más dedicada a la postulación de modelos teóricos. Además, la influencia de la lingüística en su enfoque y, sobre todo, el carácter transfronterizo de su pensamiento en 
busca de una "geografía sin adjetivo, pero con diferentes direcciones" (p.277) son notables.

"Na der grenze. Variaciones sobre un tema en Claude Raffestin" es el quinto y último capítulo de la recopilación. Centrado en las variaciones en el concepto de límite, está escrito por el geógrafo italiano Mario Nave. La trama del último capítulo utiliza un itinerario que intenta reproducir el modus operandi de Claude Raffestin, basado en la inseparabilidad entre sujeto y objeto de conocimiento. La frontera no sólo es un concepto importante en el pensamiento del autor objeto de estudio, sino que es consistente con su propia trayectoria de movilidad y su forma de pensar "liminal sin ser limitante" (p.276).

Al final, los autores también ofrecen una selección bibliográfica del trabajo de Claude Raffestin. El cuidado con la composición de la recopilación, la coherencia y el diálogo transversal entre sus diferentes partes - fieles a la propia trayectoria del autor- la minuciosidad y precisión en la exposición de los conceptos y las obras principales revelan el celo de esta publicación y ofrecen a los lectores hispanohablantes - pero no solo a ellos - una publicación que sin duda contribuirá a la difusión del pensamiento de Raffestin, ya que leer el libro nos instiga a saber más sobre su pensamiento.

La lectura de esta publicación reciente y la realización de este ensayo bibliográfico, así como el pensamiento de Claude Raffestin, tuvieron lugar en tiempos liminares, en la transición de mundos. En un momento en que la acción humana en la Tierra merece, una vez más, una observación seria, comprometida, profunda y general, sin barreras nacionalistas ni ningún otro orden sectario y limitante. En tiempos de la pandemia de COVID-19 — cuando muchos países del mundo (incluidos Italia, Francia, España y Brasil) adoptan medidas para suprimir la circulación en sus territorios, cierran las fronteras terrestres, fluviales y aéreas, e imponen medidas sanitarias, a veces autoritarias, para combatir el nuevo coronavirus - los conceptos de territorio, frontera y poder a los que el trabajo de Raffestin ha dedicado una contribución significativa, adquieren una nueva importancia.

Los mapas para describir la propagación de la enfermedad son producidos exhaustivamente a diario. Estas representaciones cartográficas se utilizan para ratificar, en muchas situaciones, el confinamiento y, a menudo, también se utilizan para alimentar teorías de conspiración xenófobas, como las que hoy afectan a las relaciones económicas y diplomáticas entre Brasil y China. Por otro lado, la desproporción entre la velocidad y el alcance del virus y los insumos para el tratamiento de la enfermedad revelan la geopolítica de la pandemia, tan fatalmente expuesta por la piratería de productos chinos en los aeropuertos de América del Norte. Todos estos eventos nos impulsan a cuestionar, una vez más, las relaciones entre el poder y el espacio, aquellas a las que Raffestin dedicó una parte importante de su trayectoria político-intelectual.

Flávia Melo

Universidad Complutense de Madrid Email: fmelo@ucm.es 